\title{
Author Correction: Lattice strain-enhanced exsolution of nanoparticles in thin films
}

\author{
Hyeon Han (10 1,2, Jucheol Park ${ }^{3}$, Sang Yeol Nam³ ${ }^{3,4}$, Kun Joong Kim,7, Gyeong Man Choi, ${ }^{1,5}$, Stuart S.P. Parkin², \\ Hyun Myung Jang (iD ${ }^{1,8} \&$ John T.S. Irvine (i) ${ }^{6}$
}

Correction to: Nature Communications https://doi.org/10.1038/s41467-019-09395-4, published online 1 April 2019.

The original version of this Article contained an error in the Data Availability section, which incorrectly read 'The data that support the findings of this study are available from the corresponding authors upon request.' The correct version replaces this sentence with 'The research data underpinning this publication can be accessed at https://doi.org/10.17630/21d12144-58ef-4f82-acd0-ba3c9a44ed72'. This has been corrected in both the PDF and HTML versions of the Article.

Published online: 02 May 2019

Open Access This article is licensed under a Creative Commons Attribution 4.0 International License, which permits use, sharing, adaptation, distribution and reproduction in any medium or format, as long as you give appropriate credit to the original author(s) and the source, provide a link to the Creative Commons license, and indicate if changes were made. The images or other third party material in this article are included in the article's Creative Commons license, unless indicated otherwise in a credit line to the material. If material is not included in the article's Creative Commons license and your intended use is not permitted by statutory regulation or exceeds the permitted use, you will need to obtain permission directly from the copyright holder. To view a copy of this license, visit http://creativecommons.org/licenses/by/4.0/.
\end{abstract}

(C) The Author(s) 2019

\footnotetext{
${ }^{1}$ Department of Materials Science and Engineering, Pohang University of Science and Technology (POSTECH), Pohang 37673 , Republic of Korea. ${ }^{2}$ Max Planck Institute of Microstructure Physics, Weinberg 2, Halle (Saale) 06120, Germany. ${ }^{3}$ Gyeongbuk Science \& Technology Promotion Center, Gumi Electronics \& Information Technology Research Institute, Gumi 39171, Republic of Korea. ${ }^{4}$ Department of Materials Science and Engineering, Kumoh National Institute of Technology, Gumi 39177, Republic of Korea. ${ }^{5}$ 1Fcell Inc., Pohang 37673, Republic of Korea. ${ }^{6}$ School of Chemistry, University of St Andrews, St Andrews KY16 9ST Scotland, UK. ${ }^{7}$ Present address: Department of Materials Science and Engineering, Massachusetts Institute of Technology, Cambridge, MA 02139, USA. ${ }^{8}$ Present address: Research Institute of Advanced Materials, Seoul National University, Seoul 08826, Republic of Korea. Correspondence and requests for materials should be addressed to S.S.P.P. (email: stuart.parkin@mpi-halle.mpg.de) or to H.M.J. (email: hmjang@postech.ac.kr) or to J.T.S.I. (email: jtsi@st-andrews.ac.uk)
} 